\title{
Evidence for Existence of A and B Form Monoamine Oxidase in Mitochondria from Dog Platelets
}

\author{
Toshio OBATA, Toru EGASHIRA and Yasumitsu YAMANAKA \\ Department of Pharmacology, Medical College of Oita, \\ 1-1506. Idaigaoka. Hazama-cho. Oita 879-56. Japan
}

Accepted February 16, 1987

\begin{abstract}
It is known that platelet MAO appears to behave more like the B-form enzyme than the A-form enzyme based on inhibitor sensitivity and substrate specificity. However, dog platelets showed a different substrate specificity such as high activity with $5-H T$ and $\beta$-PEA as substrates. Moreover, dog platelet MAO was sensitive to the drugs clorgyline and harmaline with 5-HT as the substrate. while it was sensitive to the drug deprenyl with $\beta$-PEA as the substrate. These results also indicate the existence of two forms of MAO in dog platelets unlike in other platelets such as those from humans. A-form MAO from dog platelets was more stable against heat treatment at $55^{\circ} \mathrm{C}$ than $\mathrm{A}$-form MAO from dog liver and brain. On the other hand, there was no difference in the heat resistance of the three enzymes with $\beta$-PEA as the substrate. After digestion with trypsin at $37^{\circ} \mathrm{C}$ for $30 \mathrm{~min}$, it was found that MAO from dog platelets, brain and liver were mostly inhibited with 5-HT as the substrate. In contrast, MAO in brain and liver were inhibited about $10 \%$, but platelet MAO was inhibited about $50 \%$ with $\beta$-PEA as the substrate. From these results, it is considered that dog platelet MAO exists as the two forms of the enzyme and has different enzymic properties in comparison with those of MAO from dog liver and brain mitochondria.
\end{abstract}

Monoamine oxidase (MAO) occurs in many tissues (1-3) including heart, liver, kidney, spleen, platelets and the peripheral and central nervous system (4). MAO oxidatively deaminates biogenic amines such as norepinephrine, dopamine and 5-HT (4) and may play an important role in the regulation of the intracellular metabolism of these neurotransmitters. Recently, alterations in activity of serotonergic and catecholaminergic neurons have been suggested in affective disorder and schizophrenia (5-7). In addition, alterations in platelet MAO activity in affective disorder and schizophrenia were described $(8,9)$. However, there have been few studies on the possible physiological relationship between platelet MAO activity and any psychiatric diagnosis. So, it is considered necessary to investigate the enzymic properties of platelet MAO. Recently, it has been reported that human platelet MAO is a single enzyme and appears to behave more like the B-form enzyme than the A-form enzyme $(10,11)$. None of these investigations, however, provided any information about the existence of multiple forms of MAO in dog platelets. In this present study, to determine whether or not dog platelet MAO exists as the two forms of the enzyme. the substrate specificities and sensitivities to selective MAO inhibitors or trypsin and heat treatment were studied.

\section{Materials and Methods}

1. Preparation of platelets: Blood samples were obtained from a dog. After $3.8 \%$ sodium citrate was added to the sample, the blood was centrifuged at 1100 r.p.m. for $10 \mathrm{~min}$ to remove the red cells, and then the supernatant was centrifuged at $3000 \mathrm{~g}$ for $30 \mathrm{~min}$. The pellet was suspended in 10 volumes of 0.01 $M$ potassium phosphate buffer $(\mathrm{pH} 7.4)$. This suspension was recentrifuged at $20000 \mathrm{~g}$ for $30 \mathrm{~min}$, and the pellet was resuspended in 
3 volume of $0.01 \mathrm{M}$ potassium phosphate buffer $(\mathrm{pH} \mathrm{7.4)}$ and used as the enzyme preparation. Dog brain and liver mitochondria were prepared as described earlier by differential centrifugation (12). Protein contents in the enzyme preparations were assayed by the method of Lowry et al. (13) with bovine serum albumin as the standard.

2. Monoamine oxidase assay: MAO activity was assayed radiochemically (14), as described previously, with $\left[{ }^{14} \mathrm{C}\right]$-tyramine $\left[{ }^{14} \mathrm{C}\right]-5-\mathrm{HT}$ or $\left[{ }^{14} \mathrm{C}\right]-\beta$-phenylethylamine $(\beta-$ PEA) after dilution with the respective unlabelled amines as substrates. The standard assay mixture contained $20 \mu$ of mitochondrial suspension, 20 /l of $0.1 \mathrm{M}$ phosphate buffer, $\mathrm{pH} 7.4$, and $140 \mu$ distilled water. The reaction was started by adding 20 $\mu l$ of substrate solution. The incubation was carried out at $37^{\circ} \mathrm{C}$ for $80 \mathrm{~min}$, and then $200 "$ "l of $2 \mathrm{~N} \mathrm{HCl}$ was added to stop the reaction. The final substrate concentrations used were approx. $100 \varkappa \mathrm{M}$ tyramine, $100, \iota \mathrm{M}$ 5 -HT and $10 \mu \mathrm{M} \beta$-PEA. Metabolites formed in this enzyme reaction were extracted with an ethyl acetate-benzene mixture $(1: 1 \mathrm{~V} / \mathrm{V})$ saturated with water, and radioactivity in the extract was measured in a Beckman LS-9000 scintillation spectrometer. In inhibition studies, enzyme preparations were preincubated at $37^{\circ} \mathrm{C}$ for $1 \mathrm{hr}$ with clorgyline and deprenyl or for $10 \mathrm{~min}$ with harmaline to inhibit either A-form MAO or B-form MAO before addition of the substrate. Then, the remaining MAO activity was determined. Specific activity was expressed as nmoles/ $\mathrm{min} / \mathrm{mg}$ protein.

3. Thermal inactivation of dog platelet MAO: Blood platelet suspensions were preincubated at $55^{\circ} \mathrm{C}$ for various incubation times, and then quickly chilled, and residual MAO activity was determined with tyramine, 5 -HT or $\beta$-PEA as the substrate. The values were expressed as percent of the control

4. Sensitivity to trypsin digestion of dog platelet MAO: Dog platelets were preincubated in the presence of trypsin $(0.05$ $\mathrm{mg} / \mathrm{mg}$ protein) at $37^{\circ} \mathrm{C}, \mathrm{pH} 7.4$, for various time intervals prior to the determination of MAO activity. MAO activities in aliquots of the control (untreated) and trypsin treated mitochondria were determied at $37^{\circ} \mathrm{C}, \mathrm{pH}$
7.4, with tyramine, $5-H T$ and $\beta$-PEA as substrates, respectively. The values were expressed as percent of the control.

5. Chemicals: $5\left[2-{ }^{14} \mathrm{C}\right]-$ Hydroxytryptamine binoxalate $(51.5 \mathrm{mCi} / \mathrm{mmol}), \quad\left[1-{ }^{14} \mathrm{C}\right]-$ tyramine hydrochloride $(55.0 \mathrm{mCi} / \mathrm{mmol})$ and $\beta-\left[1-{ }^{14} \mathrm{C}\right]$-phenylethylamine hydrochloride $(50.2 \mathrm{mCi} / \mathrm{mmol})$ were purchased from New England Nuclear, Boston, MA, U.S.A. Clorgyline was a gift from May \& Baker. Ltd., Dagenham. Essex. England. Deprenyl was a gift from Dr. J. Knoll, Dept. of Pharmacology. Semmelweis University of Medicine, Budapest. Hungary. 5-Hydroxytryptamine creatinine sulphate, tyramine hydrochloride. harmaline hydrochloride and trypsin were purchased from Sigma Chemical Co., St. Louis, MO, U.S.A. $\beta$-Phenylethylamine hydrochloride was obtained from Tokyo Chemical Industries, Co., Ltd., Japan.

\section{Results}

1. Substrate specificity of dog brain, liver and platelet mitochondrial MAO: Comparisons of the substrate specificities of dog brain, liver and platelet mitochondrial $\mathrm{MAO}$ with tyramine, 5-HT and $\beta$-PEA as substrates are shown in Table 1. When brain and liver mitochondria from dogs were used as the enzyme preparation, the highest MAO activity was obtained with $\beta$-PEA as the substrate, followed by tyramine and 5-HT: in platelet mitochondria, the highest MAO activity was obtained with 5-HT as a substrate.

2. Inhibition of MAO activity in dog platelet mitochondria by clorgyline and deprenyl: Inhibition of MAO in mitochondria from dog platelets by clorgyline as the $A$ form MAO inhibitor with 5-HT as the A-form MAO substrate and inhibition by deprenyl as the $\mathrm{B}$-form MAO inhibitor with $\beta$-PEA as the B-form MAO substrate are shown in Fig. 1. After incubation at $37^{\circ} \mathrm{C}$ for $60 \mathrm{~min}$ with clorgyline, MAO activity with $5-\mathrm{HT}$ as the substrate was highly sensitive, and the activity with $\beta$-PEA was less sensitive (Fig. 1. upper). When corresponding experiments were performed with deprenyl. the opposite results were obtained (Fig. 1, lower).

3. Thermal inactivation of dog platelet MAO: When dog platelets were treated at 
Table 1. Substrate specificities of dog liver, brain and platelet mitochondrial MAO

Substrate

$\begin{array}{lrrr} & \text { liver } & \text { brain } & \text { platelet } \\ \text { Tyramine } & 6.32 & 4.30 & 0.10 \\ 5 \text {-HT } & 1.08 & 3.49 & 0.14 \\ \beta \text {-PEA } & 46.46 & 15.29 & 0.09\end{array}$

MAO activity was determined by radiometric assay. Experimental conditions were described in the Methods. Substrate concentrations used were $100 \mu \mathrm{M}$ tyramine. $100 \mu \mathrm{M} 5-\mathrm{HT}$ and $10 \mu \mathrm{M} \beta$-PEA as a final concentration. MAO activities were expressed as nmoles $/ \mathrm{min} / \mathrm{mg}$ protein.

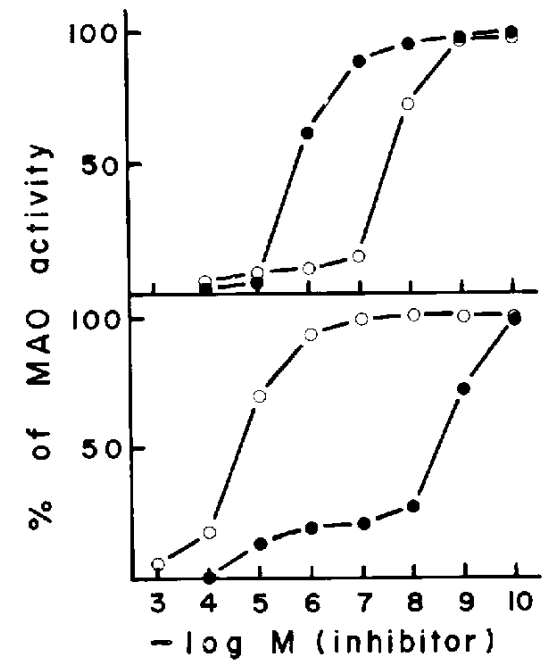

Fig. 1. Inhibition of MAO activity in dog platelet mitochondria toward $5-\mathrm{HT}$ and $\beta$-PEA by deprenyl and clorgyline. The mitochondrial preparation was preincubated with clorgyline (upper) and deprenyl (bottom) at $37^{\circ} \mathrm{C}$ for $1 \mathrm{hr}$ in a total volume of $200 \mu \mathrm{l}$ of phosphate buffer. MAO activity was assayed radiometrically by addition of substrate $5-\mathrm{HT}$ $(\mathrm{O}-\mathrm{O})$ and $\beta$-PEA $(-\mathrm{C})$ at $37^{\circ} \mathrm{C}$ for $30 \mathrm{~min}$.

$55^{\circ} \mathrm{C}$, progressive inhibition of activity was observed, and inhibition was $45 \%$ at 30 min with $5-\mathrm{HT}$ as the substrate. On the other hand, in the case of dog brain and liver, $85 \%$ and $95 \%$ inhibition were observed at $30 \mathrm{~min}$. respectively. When $\beta$-PEA was used as a substrate, the dog platelet MAO was heat labile in comparison to when 5-HT was used as the substrate (Fig. 2).

4. Sensitivity to trypsin digestion of dog platelet MAO: Dog platelet, liver and brain mitochondria were preincubated in the

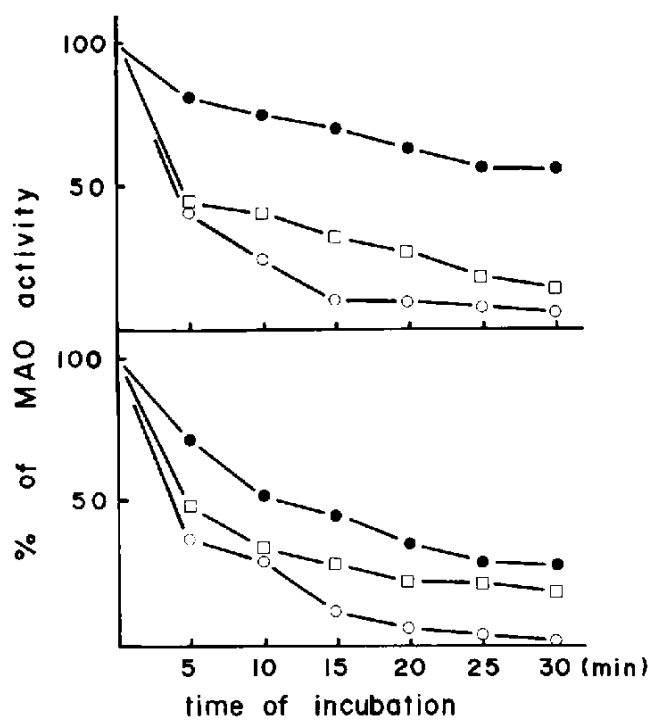

Fig. 2. Effects of heat treatment on the activity of mitochondrial MAO in dog platelets, brain and liver toward 5-HT and $\beta$-PEA. Each of the mitochondrial preparations, platelet $(-\infty)$ ), brain ( $1-\square)$ and liver $(\mathrm{O}-\mathrm{O})$, were incubated at $55^{\circ} \mathrm{C}$ for 5 to $30 \mathrm{~min}$. The remaining activity is expressed as $\%$ of the control MAO activity with $5-H T$ (upper) and $\beta$-PEA (bottom) as substrate.

presence of trypsin for various time intervals prior to determination of MAO activity. After the treatment by trypsin for $30 \mathrm{~min}$, MAO activities in dog brain, liver and platelet were inhibited $85,80 \%, 90 \%$ with $5-\mathrm{HT}$ as the substrate, respectively (Fig. 3, upper). On the other hand, in the case of $\beta$-PEA as the substrate, it was found that MAO activities in the dog brain and liver were lost by only $25 \%$, but $\mathrm{MAO}$ activity in dog platelets remained $35 \%$ at $4 \mathrm{hr}$ (Fig. 3, lower). 


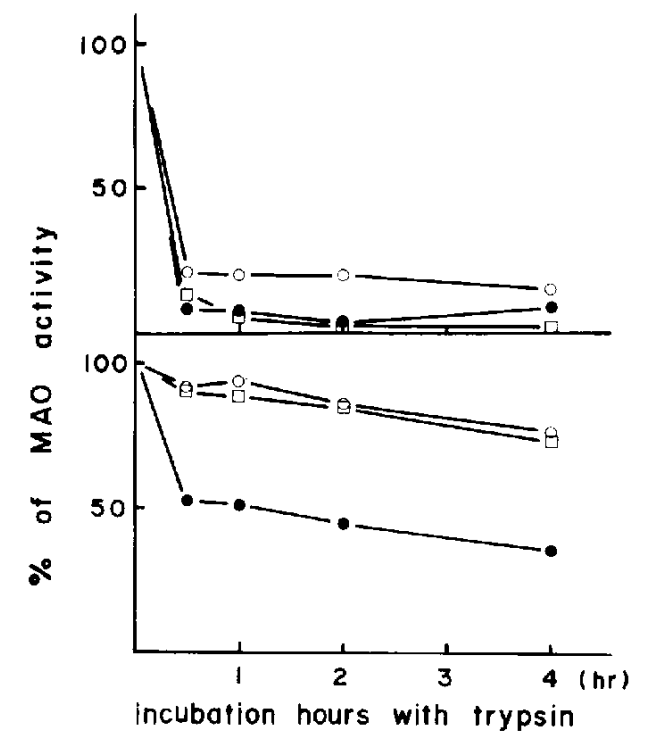

Fig. 3. Sensitivity to trypsin digestion of mitochondrial MAO in dog platelets, brain and liver toward 5-HT and $\beta$-PEA. Each of the mitochondrial preparations, platelet $(-\square)$, brain $([-\square)$ and liver $(\mathrm{O}-\mathrm{O})$, were preincubated in the presence of trypsin $\left(0.05 \mathrm{mg} / \mathrm{mg}\right.$ protein) at $37^{\circ} \mathrm{C}, \mathrm{pH}$ 7.4. for the various time intervals indicated prior to the determination of MAO activity. At the time indicated. MAO activities in aliquots of the control (untreated) and trypsin treated mitochondria were determined by radiochemically by addition of $5-\mathrm{HT}$ (upper) and $\beta$-PEA (bottom) at $37^{\circ} \mathrm{C}$ for $30 \mathrm{~min}$. The results are expressed as $\%$ of the control MAO activity.

5. Kinetics of inhibition of dog platelet MAO by clorgyline: The inhibitions by clorgyline of dog platelet MAO with tyramine, $5-H T$ and $\beta$-PEA as substrates are shown by Lineweaver-Burk plots (Fig. 4). The inhibition was noncompetitive, and the $K_{m}$ value for 5 -HT was $145 \mu \mathrm{M}$. As shown in Fig. 5, the inhibitions by clorgyline of dog brain and liver MAO were also noncompetitive. These $K_{m}$ values for 5 - HT were $80 \mu \mathrm{M}$ and $145 \mu \mathrm{M}$, respectively.

\section{Discussion}

MAO is classified into two forms, A-form and $B$-form MAO (15-17). It has recently been reported that MAO may exist in multiple forms depending on tissue and species (18. 19). Rat organs such as spleen and testis

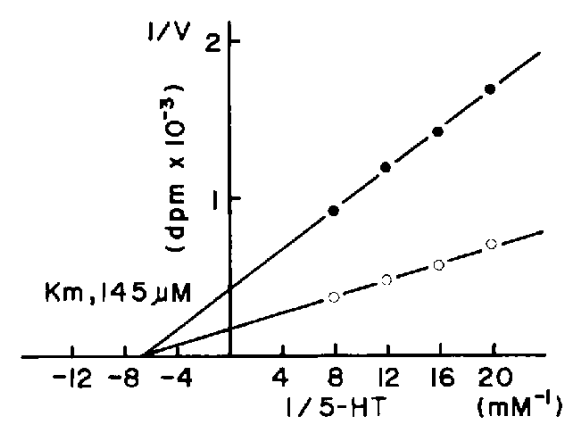

Fig. 4. Lineweaver-Burk plots of dog platelet mitochandrial MAO toward 5-HT. LineweaverBurk plots of the reciprocal of the initial velocity of 5-HT oxidation against the reciprocal of the 5-HT concentration in the absence $(\mathrm{O}-\mathrm{O})$ and presence (-) of $1 \times 10^{-8} \mathrm{M}$ clorgyline.

(20), and the neuroblastoma and glioma of mouse $(21,22)$ and human placenta (12, 23) contain predominantly a single species of the A-form MAO. In contrast. B-form MAO activity is found in the mouse and rabbit liver or human platelets $(11,24)$. In general, it is known that the various platelet MAO's appear to behave more like the B-form enzyme than the A-form enzyme based on inhibitor sensitivity and substrate specificity $(11,24)$. However, dog platelet MAO showed a different substrate specificity, that is, 5-HT was also deaminated highly. Moreover, dog platelet MAO was sensitive to the drugs clorgyline and harmaline (preferentially Aform MAO inhibitors) and was resistant to the drug deprenyl (preferentially a B-form MAO inhibitor) with $5-\mathrm{HT}$ as the substrate. When corresponding experiments were performed with $\beta$-PEA (substrates for B-form MAO), the opposite results were obtained. These results also indicate the existence of two forms of MAO in dog platelets unlike in other platelets such as those from humans.

In general, A-form MAO is readily digested by trypsin and is heat stable as compared to the $B$-form MAO $(12,25,26)$. To determine whether or not A-form MAO in dog platelets also show similar properties to A-form MAO in brain and liver, the thermostability and trypsin digestion of dog platelet MAO were compared with those of MAO from dog liver and brain. A-form MAO from platelets was more stable against $55^{\circ} \mathrm{C}$ incubation than 


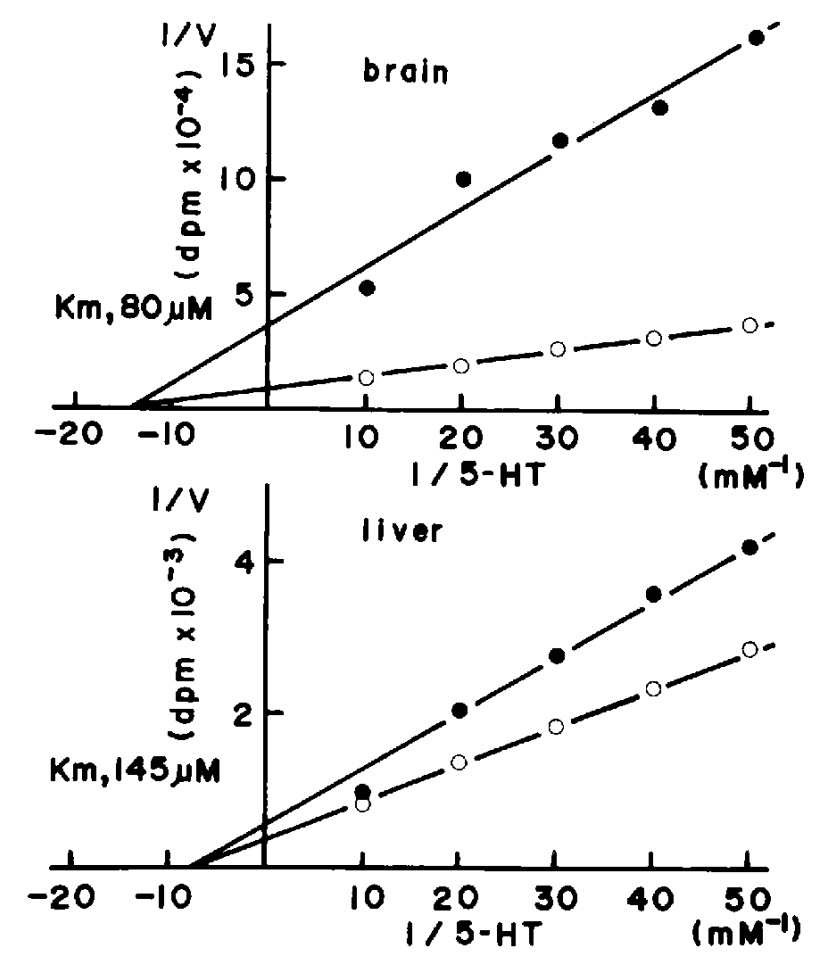

Fig. 5. Lineweaver-Burk plots of dog brain (upper) and liver (bottom) mitochondrial MAO toward 5-HT. The method of plotting is the same as that of Fig. 4.

A-form MAO from liver and brain. On the other hand, there were no differences in the abilities of the three enzymes to resist heat with $\beta$-PEA as the substrate. After treatment with trypsin at $37^{\circ} \mathrm{C}$ for $30 \mathrm{~min}$, it was found that $\mathrm{MAO}$ in platelets, brain and liver were mostly inhibited with $5-H T$ as the substrate. In contrast, MAO in brain and liver were inhibited by about $10 \%$, but $\mathrm{MAO}$ in platelets was inhibited by about $50 \%$ with $\beta$-PEA as the substrate. From these results, A-form $\mathrm{MAO}$ in platelets also was heat stable and sensitive to trypsin digestion, like the A-form in other organs. These findings are in line with the results of Houslay and Tipton (27) and Ekstedt and Oreland (26) that A-form $M A O$ is more dependent on phospholipids for its activity and that the thermostability and resistance to trypsin digestion of the enzyme are influenced by the chemical nature of the environment surrounding the enzyme protein.

Recent studies using platelet MAO activity as a possible index of central nervous system events have found altered activity of platelet MAO in depressed and schizophrenic patients (28). In addition, Murphy and Wyatt (29) reported reduced platelet MAO activity in chronic schizophrenic individuals (30, 31). Human platelets contains solely B-form MAO (11). However, B-form MAO can not deaminate $5-H T$, although $5-H T$ is present at high concentration in platelets. So, in the case of human platelets, we must consider the possibilities that 5-HT is metabolized by other enzymic processes or is deaminated by a clorgyline/deprenyl insensitive form of MAO (11). At present, however, dog platelet MAO deaminated $5-\mathrm{HT}$ and $\beta$-PEA, and it is sensitive to low concentrations of clorgyline and depreny!, that is, contain also A-form and B-form MAO. We do not have any information which provides an explanation of this difference.

It seems likely that dog platelet $M A O$ is different from other species and that it has different physiological properties. Further in vivo studies using MAO inhibitors are under 
way in our laboratory to elucidate the physiological function of MAO in platelets.

\section{References}

1 Schnaitman, C., Erwin, V.G. and Greenawalt, J.W.: The submitochondrial localization of monoamine oxidase. J. Cell Biol. 32, 719-735 (1967)

2 Schnaitman, C. and Greenawalt, J.W.: Enzymatic properties of the inner and outer membranes of rat liver mitochondria. J. Cell Biol. 38, 158-175 (1968)

3 Alles, G.A. and Heegard, E.V.: Substrate specificities of amine oxidase. J. Biol. Chem. 147, 487-503 (1943)

4 Sandler, M. and Youdim, M.B.H.: Multiple forms of monoamine oxidase. Functional significance. Pharmacol. Rev. 24, 331-348 (1972)

5 Goodwin, F.K. and Potter, W.Z.: Norepinephrine metabolite studies in affective illness. in Catecholamines: Basic and Clinical Frontiers. Vol. II, Edited by Usdin, E., Kopin, I.J. and Barchas, J., Pergamon Press, New York (1979)

6 Shekin, W.O., Dekirmenjia, H. and Chapel, J.L.: Norepinephrine metabolism and clinical response to dextroamphetamine in hyperactive boys. J. Pediatr. 95, 389-394 (1979)

7 Shaywitz, B.A., Cohen, D.J. and Boweres, M.G.: CSF monoamine metabolites in children with minimal brain dysfunction-evidence for alternations of brain dopamine. J. Pediatr. 90, 67-71 (1977)

8 Gershn, E.S., Kessler, L.R. and Bunney, W.E.: Monoamine enzymes and inhibitors in affective illness. In Structure and Function of Monoamine Enzymes, Edited by Usdin, E., Weiner, N. and Youdim. M.B.H., Marcel Dekker, New York (1977)

9 Buchsbaum, M.S. and Murphy, D.L.: Monoamine enzymes and inhibitors in affective illness. In Peripheral Monoamine Enzyme Indicators of Psychological Function and Psychiatric Susceptibilities, Edited by Usdin, E., Weiner, N. and Youdim, M.B.H., Marcel Dekker. New York (1977)

10 Collins, G.G.S. and Sandler, M.: Human blood platelet monoamine oxidase. Biochem. Pharmacol. 20, 289-296 (1970)

11 Donnelly, C.H. and Murphy, D.L.: Substrateand inhibitor-related characteristics of human platelet monoamine oxidase. Biochem. Pharmacol. 26, 853-858 (1976)

12 Kikuchi, R. and Kinemuchi, H.: Evidence for existence of type A. MAO in mitochondria from human placenta. Folia Pharmacol. Japon. 74,
763-772 (1978) (Abs. in English)

13 Lowry, O.H., Rosebrough, N.J., Farr, A.L. and Randall, R.J.: Protein measurment with the Folin phenol reagent. J. Biol. Chem. 193, 265275 (1951)

14 Fowler, C.J., Ekstedt, B., Egashira, T., Kinemuchi, $H$. and Oreland, L.: The interaction between human platelet monoamine oxidase, its monoamine substrates and oxygen. Biochem. Pharmacol. 28, 3063-3068 (1979)

15 Johnston, J.P.: Some observations upon a new inhibitor of monoamine oxidase in brain tissue. Biochem. Pharmacol. 17, 1285-1297 (1968)

16 Knoll, J. and Magyar, K.: Some puzzling pharmacological effects of monoamine oxidase inhibition. Adv. Biochem. Psychopharmacol. 5, 393-408 (1972)

17 Neff, N.H. and Yang, H.-Y.T.: Another look at the monoamine oxidase and the monoamine oxidase inhibitor drugs. Life Sci. 14, 2061-2074 (1974)

18 Shin, J.-H.C. and Eiduson, S.: Multiple forms of monoamine oxidase in the developing brain. Nature 224, 1309-1310 (1969)

19 Gorkin, V.Z: Separation of rat liver mitochondrial amine oxidase. Experientia 25, 1142-1143 (1969)

20 Tipton, K.F., Houslay, M.D. and Manyle, T.J.: The nature and location of the multiple forms of monoamine oxidase. In Monoamine Oxidase and Its Inhibition. Edited by Wolstenholme, G.E.W. and Knight, J., p. 5-16. Elsevier, Amsterdam (1976)

21 Donnely, C.H., Richelson, E. and Murphy, D.L.: Properties of monoamine oxidase in mouse neuroblastoma NIE-115 cells. Biochem. Pharmacol. 25, 1639-1643 (1976)

22 Murphy, D.L., Donnely, C.H. and Richelson, E.: Substrate- and inhibitor-related characteristics of monoamine oxidase in $\mathrm{C} 6$ rat grial cells. J. Neurochem. 26, 1231-1235 (1976)

23 Egashira, T.: Studies on monoamine oxidase. XVIII. Enzymic properties of placental monoamine oxidase. Japan. J. Pharmacol. 26, 493$500(1976)$

24 Edwards, D.J. and Burns, M.O.: Effects of tricyclic antidepressants upon human platelet monoamine oxidase. Life Sci. 15, 2045-2058 (1974)

25 McCauley, R.: Properties of a monoamine oxidase from rat liver mitochondrial outer membranes. Arch. Biochem. Biophys. 189, 8-13 (1978)

26 Oreland, L. and Ekstedt, B.: Soluble and membrane-bound pig liver mitochondrial mono- 
amine oxidase: Thermostability, tryptic digestibilty and kinetic properties. Biochem. Pharmacol. 21, 2479-2488 (1972)

27 Houslay, M.D. and Tipton, K.F.: The nature of the electrophoretically separable multiple forms of rat liver monoamine oxidase. Biochem. J. 135 , 173-186 (1973)

28 Friedman, E., Shopsin, B., Sathananthan, G. and Gershon, S.: Blood platelet monoamine oxidase activity in psychiatric patients. Am. J. Psychiatry 131, 1392-1394 (1974)

29 Murphy, D.L. and Wyatt, R.J.: Reduced monoamine oxidase activity in blood platelets from schizophrenic patients. Nature 238, 225-226 (1972)

30 Bridge, T.P., Soldo, B.J., Phelps, B.H., Weise, C.D., Francak, M.J. and Wyatt, R.J.: Platelet monoamine oxidase activity: demographic characteristics contribute to enzyme activity variability. J. Gerontol. 40, 23-28 (1985)

31 Schatzberg, A., Rothschild, A.J., Gershon, B., Lerbinger, J. and Schldkraut, J.J.: Toward a biochemical classification of depressive disorders IX DST results and platelet MAO activity. Br. J. Psychiatry 146, 633-637 (1985) 